\title{
Hypoxic-Ischaemic Encephalopathy and the Blood-Brain Barrier in Neonates
}

\author{
Wei Ling Amelia Lee ${ }^{a} \quad$ Adina T. Michael-Titus $^{b}$ Divyen K. Shah ${ }^{c, d}$ \\ ${ }^{a}$ Barts and the London School of Medicine and Dentistry, Centres for ${ }^{b}$ Neuroscience and Trauma and \\ 'Genomics and Child Health, Blizard Institute, Barts and The London School of Medicine and Dentistry, \\ Queen Mary University of London, and ${ }^{\mathrm{d}}$ The Royal London Hospital, Barts Health NHS Trust, London, UK
}

(C) S. Karger AG, Basel PROOF Copy
for personal
use only ANY DISTRIBUTION OF THIS ARTICLE WITHOUT WRITTEN CONSENT FROM S. KARGER AG, BASEL IS A VIOLATION OF THE COPYRIGHT.

\section{Keywords}

Hypoxic-ischaemic encephalopathy - Blood-brain barrier Neurovascular unit - Vascular endothelial growth factor . Molecular Trojan horse technology · Endothelial progenitor cells

\begin{abstract}
This review aims to highlight a possible relationship between hypoxic-ischaemic encephalopathy (HIE) and the disruption of the blood-brain barrier (BBB). Inflammatory reactions perpetuate a large proportion of cerebral injury. The extent of injury noted in HIE is not only determined by the biochemical cascades that trigger the apoptosis-necrosis continuum of cell death in the brain parenchyma, but also by the breaching of the BBB by pro-inflammatory factors. We examine the changes that contribute to the breakdown of the BBB that occur during HIE at a macroscopic, cellular, and molecular level. The BBB is a permeability barrier which separates a large majority of brain areas from the systemic circulation. The concept of a physiological BBB is based at the anatomical level on the neurovascular unit (NVU). The NVU consists of various cellular components that jointly regulate the exchanges that occur at the interface between the systemic circulation and the brain parenchyma. There is increased understanding of the contribution of the compo-
\end{abstract}

\section{KARGER}

(C) 2017 S. Karger AG, Basel

E-Mail karger@karger.com

www.karger.com/dne nents of the NVU, e.g., astrocytes and pericytes, to the maintenance of this physiological barrier. We also explore the development of therapeutic options in HIE, such as harnessing the transport systems in the BBB, to enable the delivery of large molecules with molecular Trojan horse technology, and the reinforcement of the physical barrier with cell-based therapy which utilizes endothelial progenitor cells and stem cells.

두 2017 S. Karger AG, Basel

\section{Introduction}

The unifying disturbance to neural tissue in hypoxicischaemic encephalopathy (HIE) is a deficit in oxygen supply [1]. This can occur because of hypoxia, a diminished amount of oxygen in the blood supply, and ischaemia, a diminished amount of blood perfusing the brain. It is important to recognize that the resulting damage to the brain tissue continues to develop hours to days after the initial HI episode in term newborns [2-4]. Northington et al. [5] propose the concept of "continuum in cell death," whereby the degeneration of neurons lies along a continuum between apoptosis and necrosis. This concept emphasizes the variety of mechanisms of injury and the complex cellular interactions that occur in response to it, 
which ultimately contribute to cell death. After the relative success of translating mild therapeutic hypothermia from the bench to the bedside for neuroprotection, adjunctive treatments which aim to further increase neuroprotection are undergoing exploration.

In this paper, we review the relationship between HIE and the blood-brain barrier (BBB). More than just being a physical barrier formed by tight junctions between the endothelial cells, the BBB is a dynamic physiological barrier which regulates the passage of hydrophilic molecules into the central nervous system (CNS) via transporters and enzymes [6-9]. There is active communication between endothelial cells, pericytes, astrocytes, microglia, the structural basement membrane, and the extracellular matrix (ECM), which is vital for the modulation and the maintenance of the selective permeability of the BBB. Perivascular macrophages, which are adjacent to endothelial cells immediately beyond the basement membrane, also have a regulatory role. This complex system is referred to as the neurovascular unit (NVU) [10, 11], and it underlies the $\mathrm{BBB}$ function by acting as an exchange interface between the blood and the CNS. It enables the CNS environment to remain stable despite fluctuations in the composition of plasma and brain interstitial fluid, thus preventing interference with signal transmission. The progress in the characterization of the $\mathrm{BBB}$ structure through proteomics [12] and the improvement in drug delivery by taking advantage of the endogenous transporting systems of the $\mathrm{BBB}[13,14]$ hint at the potential of the $\mathrm{BBB}$ to take a more prominent role in our understanding and management of HIE. However, this discussion also serves to highlight the challenges and controversies in our understanding of the $\mathrm{BBB}$ and its relationship to HIE. The observations discussed in this review originate from a variety of experimental models (summarized in Table 1).

\section{Defining the Blood-Brain Barrier by Its Morphology and Function}

A cross-section of the NVU can be visualized as a layer of endothelial cells and interconnected junctional-protein complexes surrounded on the outside by a basement membrane which is shared with enveloping pericytes. Perivascular macrophages abut endothelial cells. Beyond the basement membrane, astrocytic end feet are in direct communication with the vascular lining and thus act as a cellular link with neurons, all of which are anchored in place by ECM proteins [6]. The significant restriction of passage of substances across the $\mathrm{BBB}$ is reflected in the high trans-endothelial electrical resistance (TEER) across the endothelial cells of the BBB, which is 50 times higher than that across the peripheral endothelium [15]. One of the main physical characteristics of the brain endothelial lining, underpinning its barrier function, lies in the complex tight junctions which limit the intercellular movement of molecules [7]. Amongst the proteins making up this structure are the transmembrane proteins occludin and claudin [16]. There is evidence that claudins contribute to the high TEER across the BBB [7], and claudin-5 shows promise as a therapeutic target as BBB permeability to small molecules of a molecular weight of $<800 \mathrm{Da}$ increases in its absence [17]. The role of other proteins, including zonula occludens proteins (ZO-1, ZO-2, and $\mathrm{ZO}-3$ ), which anchor the tight junctions to the cellular cytoskeleton, and junctional-adhesion molecules (JAM$A, J A M-B$, and JAM-C), which help regulate the tightness of the junctions, is not as well understood and requires further work [18].

\section{The Role of Pericytes}

Platelet-derived growth factor BB (PDGF-BB), secreted by the endothelial cells, forms a concentration gradient at the basement membrane and recruits pericytes to take up their position [19]. Pericytes reinforce and support the NVU; in their absence, microaneurysms form and there is rupture of the microvascular structures [20,21]. Pericytes may be important in determining BBB permeability, by inhibiting the expression of molecules promoting vascular permeability and immune cell infiltration. Pericytes regulate functional aspects of the $\mathrm{BBB}$, including the formation of tight junctions and vesicle trafficking in CNS endothelial cells [22].

\section{The Role of Astrocytes}

The role of astrocytes in the BBB is less certain and is more controversial [23-25]. Studies using immunohistochemistry and co-cultures of astrocytes with endothelial cells and pericytes show that astrocytes are necessary to guide interactions between these cells, and their presence contributes to the upregulation of $\mathrm{BBB}$ properties in the endothelial lining [26]. It has been postulated that because astrocytes appear in development after the vascularization of the brain, this emphasizes their "maintenance" and supportive role.

\section{The Role of CNS Mononuclear Phagocytes}

Microglia are the most abundant myeloid cell population in the CNS. Determining the origins of microglia has
Lee/Michael-Titus/Shah 
Table 1. Summary of studies on the BBB and the models on which they were based

\begin{tabular}{|c|c|}
\hline First author [Ref.], year & Experimental model \\
\hline Colbourne [3], 1995 & 15-week-old gerbils; temporary occlusion of carotid arteries \\
\hline Geddes [4], 2016 & P7 rats; carotid artery ligation and hypoxia \\
\hline Butt [15], 1990 & infant and fetal rats (age range: 17 gestational days to P33); hyperosmotic shock and metabolic poisons \\
\hline Nitta [17], 2003 & genetically modified claudin-5-deficient newborn mice \\
\hline Lindahl [20], 1997 & PDGFB-deficient mouse embryos \\
\hline Tallquist [21], 2003 & PDGFR- $\beta$ allelic variants - mouse embryos \\
\hline Janzer [24], 1987 & neonatal rat astrocytes and meningeal cells \\
\hline Ramsauer [26], 2002 & astrocytes from rats aged $8-12$ weeks and $1-2$ days; endothelial cells and pericytes \\
\hline He [29], 2016 & mice aged $8-12$ weeks \\
\hline Wang [30], 2012 & genetically modified mice (Frizzled signalling) ranging from newborns to adults \\
\hline Liebner [31], 2008 & $\begin{array}{l}\text { genetically modified mice (Wnt signalling) ranging from embryonic to early postnatal mice }+ \text { young } \\
\text { adult mice endothelial cell culture }\end{array}$ \\
\hline Alvarez [32], 2011 & $\begin{array}{l}\text { human BBB endothelial cells + genetically modified mice (Hedgehog signalling) ranging from } \\
\text { embryos to adults }\end{array}$ \\
\hline Haqqani [36], 2013 & immortalized human brain microvascular endothelial cells \\
\hline Grontoft [37], 1954 & post-mortem of legally aborted human and rabbit fetuses \\
\hline Dziegielewska [38], 1979 & fetal sheep; early and late gestation permeability studies \\
\hline Ek [40], 2015 & P9 mice; HI model \\
\hline Muramatsu [41], 1997 & P7, P14, and P21 rats; HI model \\
\hline Chen [42], 2012 & fetal sheep ischaemia model \\
\hline Chen [43], 2006 & mammalian cancer cells \\
\hline Baskaya [44], 1997 & adult rats; traumatic brain injury \\
\hline Kumar [45], 2008 & term neonates; HIE \\
\hline Kotter [49], 2006 & adult rats; demyelination model \\
\hline Ritzel [52], 2015 & mice aged 10-12 weeks; middle cerebral artery occlusion \\
\hline $\mathrm{Hu}[53], 2012$ & mice aged 10-12 weeks; focal transient cerebral ischaemia + embryonic rat cell culture \\
\hline Breckwoldt [54], 2008 & adult mice; unilateral middle cerebral artery occlusion \\
\hline Gliem [55], 2012 & mice aged $6-10$ weeks; photothrombosis and transient middle cerebral occlusion \\
\hline Chu [56], 2015 & mice aged 8-12 weeks; occlusion of the middle cerebral artery \\
\hline Crane [57], 2014 & mouse aged $8-10$ weeks; sterile wound model \\
\hline Noda [58], 2011 & mouse embryonic neuronal and microglial cells \\
\hline Elliott [59], 2009 & mice aged 8-12 weeks; murine air pouch model, mouse aged $4-5$ weeks; thymic clearance model \\
\hline Feng [62], 2008 & P7 rats; HIE \\
\hline Schmid-Brunclik [63], 2008 & newborn rat astrocytes \\
\hline Wang [64], 2001 & brain microvessel endothelial cells from bovine grey matter \\
\hline Kaur [65], 2006 & adult rats; hypoxia model \\
\hline Chen [67], 2008 & P7 rats; HI model \\
\hline Sheldon [68], 2009 & P7 mice; hypoxia and HI model \\
\hline Nedelcu [69], 1999 & P7 rats; HI model \\
\hline Manley [74], 2000 & adult mice; AQP4 deficient and middle cerebral occlusion \\
\hline $\mathrm{Fu}[76], 2007$ & $\mathrm{P} 3$ rat astrocytes \\
\hline Heo [78], 1999 & adolescent baboons; middle cerebral artery occlusion \\
\hline Shankaran [80], 2005 & newborns (at least 36 weeks' gestational age); HIE \\
\hline Azzopardi [81], 2009 & newborns (at least 36 weeks' gestational age); perinatal asphyxia \\
\hline Baumann [82], 2009 & adult rats; bilateral common carotid artery occlusion \\
\hline Jurkovich [83], 1988 & cat intestine; ischaemia model \\
\hline Boado [86], 2010 & adult rhesus monkey; BBB and fusion protein studies \\
\hline Boado [87], 2010 & adult rhesus monkeys; BBB and fusion protein studies \\
\hline Zhou [89], 2011 & adult mice; 6-hydroxydopamine model of Parkinson disease \\
\hline Sumbria [90], 2012 & adult mice; reversible middle cerebral artery occlusion \\
\hline Sumbria [91], 2013 & adult mice; reversible middle cerebral artery occlusion \\
\hline Liao [92], 2013 & neonates with HIE and children with cerebral palsy \\
\hline Asahara [94], 1997 & human endothelial progenitor cells; rabbit and mouse ischaemia models \\
\hline Peichev [95], 2000 & human fetal liver cells and cord blood cells \\
\hline Zhang [97], 2002 & adult mice; middle cerebral artery occlusion \\
\hline Fan [99], 2010 & adult mice; transient middle cerebral artery occlusion \\
\hline Ohta [100], 2006 & rats aged 8-10 weeks; middle cerebral artery occlusion \\
\hline
\end{tabular}

HIE and the Blood-Brain Barrier in Neonates
Dev Neurosci

DOI: $10.1159 / 000467392$ 
been challenging due to their unique characteristics as both glial cells involved in regulating synaptic structures and immune cells surveying and responding to injury. Microglia are derived from haematopoietic stem cells in the yolk sac, differing thus from peripheral macrophages, which are derived from the bone marrow [27]. Embryonic microglia actively proliferate, maintaining a steadystate supply into adulthood, without a contribution from peripheral monocytes. Microglia are present in the CNS prior to the endothelial presence, and it has been suggested that the interaction between microglia and endothelium plays a key role in BBB formation and function. Changes in equilibrium associated with injury, however, result in the recruitment of peripheral monocytes which are able to differentiate into cells with properties similar to those of microglia (also called monocyte-derived macrophages, MDMs). The contribution of the embryonic or peripheral MDMs to the acute and chronic phases of $\mathrm{HI}$ injury has yet to be fully established.

Other mononuclear phagocytes that exist in the CNS, e.g., the perivascular macrophages which contribute to the NVU, have less well-defined roles. They originate from the bone marrow and reside in closer communion with the vasculature as opposed to the microglia, which infiltrate the CNS tissue [28]. A recent study [29] has revealed that communication with endothelial cells appears to promote polarization of the perivascular macrophages to exhibit an M2 phenotype (a concept discussed later). Indeed, it appears that only peripheral monocytes expressing genes favouring differentiation to the $\mathrm{M} 2$ phenotype are able to reconstitute previously disrupted BBB permeability. Furthermore, similarly to pericytes, perivascular macrophages can dissociate from the vasculature and contribute to the increased permeability of a disrupted BBB [29].

\section{The $B B B$ as a Dynamic Barrier}

The brain endothelial cells express BBB-specific genes that enable the development of the endothelial barrier in the absence of external influences. However, pericytes, astrocytes, perivascular macrophages, and microglia may still have a role to play in regulating and maintaining the functional characteristics of the BBB after the formation of the endothelial barrier. Recent studies show that the BBB is not an unassailable structure and that removal of the interdependent components of the NVU can result in the loss of its barrier properties [30-32].

The BBB is a functionally dynamic construct. For example, endothelial dysfunction is associated with the release of microparticles such as endothelial microvesicles and exosomes. These particles contain mixtures of proteins and other components, which are shared with the parent cell [33]. They have a diverse profile of adhesion molecules, antigen-presenting molecules, and other proteins involved in cell-to-cell signalling, and have been a recent focus of interest for their proposed role in the cellular and BBB trafficking of molecules [34]. Particularly of interest is their specificity and sensitivity as biomarkers of the involvement of the $\mathrm{BBB}$ in neurological pathologies that can be detected peripherally, as they are extruded from the brain endothelial cells into the bloodstream $[35,36]$.

\section{Maturation of the BBB}

The developmental changes in BBB morphology and function are not fully understood and much of our current understanding of the effect of hypoxia on the cerebral vasculature is derived from adult models.

In 1954, Grontoft et al. [37] demonstrated that the BBB obtained from legally aborted human fetuses was impermeable to Trypan blue dye as early as at the point of placenta separation. Their interpretation of this observation was that a functional BBB was already present at the fetal stage of human development. In addition, brain staining was noted to occur when some time had elapsed after placental separation. This was postulated, and later confirmed, to be the effect of hypoxia on the permeability of the $\mathrm{BBB}$ [23]. There is evidence that the fetal and newborn BBB may indeed be functional, at least in lower species; immunostaining reveals evidence of a functionally intact BBB in rats as early as embryonic day 16 (E16) [23].

In E60 fetal sheep, Dziegielewska et al. [38] noted that the intravascular injection of Alcian blue had reached the brain tissue, not through the tight junctions, which were observed to be well formed by E60, but via intracellular vesicles, with declining activity by E125. Thus, the idea was conceived of the earlier maturation of tight junctions, followed by the maturation of transcellular transport in the developing BBB. These 2 mechanisms have been proposed to become fully functional at different points along the timeline of development.

\section{The Effects of HI Injury on the BBB}

Important effects of HI injury on the BBB include angiogenesis and changes in permeability. Several key molecules have a role in angiogenesis, including hypoxia-

\section{4}

Dev Neurosci

DOI: $10.1159 / 000467392$
Lee/Michael-Titus/Shah 
Table 2. Summary of studies on the timeline of BBB permeability changes after HI injury

\begin{tabular}{llllll}
\hline $\begin{array}{l}\text { First author } \\
\text { [Ref.], year }\end{array}$ & $\begin{array}{l}\text { Animal } \\
\text { model }\end{array}$ & Age & $\begin{array}{l}\text { Measured indicator of BBB } \\
\text { permeability }\end{array}$ & $\begin{array}{l}\text { Earliest peak } \\
\text { of BBB } \\
\text { permeability }\end{array}$ & $\begin{array}{l}\text { Sampling time } \\
\text { after HI injury }\end{array}$ \\
\hline $\begin{array}{l}\text { Muramatsu } \\
{[41], 1997}\end{array}$ & rat & postnatal day 7 & IgG immunoreactivity & $6 \mathrm{~h}$ & $3,6,9,12,18$, and 24 h \\
\hline $\begin{array}{l}\text { Chen } \\
{[42], 2012}\end{array}$ & sheep & $\begin{array}{l}125-129 \text { gestational days } \\
(85-87 \% \text { of } \\
\text { gestation) }\end{array}$ & $\begin{array}{l}\text { calculation of blood-to-brain } \\
\text { transfer constant for } \\
\text { radioactive tracer }\end{array}$ & $4 \mathrm{~h}$ & 4,24 , and 48 h \\
\hline $\begin{array}{l}\text { Ek } \\
{[40], 2015}\end{array}$ & mouse & postnatal day 9 & $\begin{array}{l}\text { CSF-to-plasma sucrose } \\
\text { concentration ratio and } \\
\text { albumin immunoreactivity }\end{array}$ & $2 \mathrm{~h}$ & $\begin{array}{l}2,6,24, \text { and } 72 \mathrm{~h} \\
\text { (and 168 h for sucrose } \\
\text { concentration ratio) }\end{array}$ \\
\hline
\end{tabular}

inducible factor-1 ( $\left.\mathrm{HIF}_{1 \alpha}\right)$, vascular endothelial growth factor (VEGF) and erythropoietin. Angiogenesis can be divided into 2 processes: angiogenic remodelling and angiogenic sprouting [39]. The latter involves the replacement of old vessels, which are broken down, with new immature vessels, leaving the BBB vulnerable to oedematous disruption and mechanical stress. This is in comparison to the former, whereby existing vascular networks undergo changes leading to the development of a mature, stable vasculature contributing to the BBB.

$\mathrm{BBB}$ permeability has been measured by various methods and the models used to study permeability in response to $\mathrm{HI}$ insult have been diverse. There is consensus that there is an increased early BBB permeability, peaking at between 2 and $4 \mathrm{~h}$ after insult in most neonatal injury models (Table 2) [40-42].

In the neonatal injury models, there is less compelling evidence of a delayed second phase of increased BBB permeability, which has been noted in the adult rat model $[43,44]$. The BBB in human babies with HIE shows increased permeability as assessed by comparing the concentrations of albumin in cerebrospinal fluid (CSF) versus plasma [45]. Equally as important, this study also lends support to the proposed relationship between HIE and the BBB, suggesting free radical injury as an amplification factor in the pathophysiological processes of both HIE and BBB dysfunction.

Whether or not the BBB experiences a second phase of increased permeability after HI injury, there is early activation of mechanisms that lead to the eventual restoration of BBB function after the insult, as demonstrated by the observation of an upregulation in the transcription and expression of tight-junction proteins in the neonatal mouse and the fetal sheep model [40, 42].

HIE and the Blood-Brain Barrier in Neonates

\section{The Effects of HI Injury on the Cellular Components of the NVU}

Engelhardt et al. [46] demonstrated that the endothelial cells are more susceptible to hypoxia-induced injury, as seen by a disruption in their cellular cytoskeleton structure, than pericytes and astrocytes which retain the cytoskeleton arrangement even with prolonged hypoxia. This was discussed in the context of the oxygen concentration these cells are exposed to in the normal brain environment, whereby astrocytes and pericytes occupy areas exposed to lower oxygen concentrations than the endothelial cells. The case becomes more complex when it is noted that the proliferation of pericytes and astrocytes is downregulated when exposed to hypoxia whereas endothelial cells continue to proliferate despite this being counterproductive to the conservation of energy and, ultimately, their survival. For endothelial cells, this is further associated with a rapid induction of the $\mathrm{HIF}_{1}$ protein and $\mathrm{BBB}$ disruption.

Microglia are the first immune cells of myeloid origin to respond to signals of inflammation such as damageassociated molecular patterns (DAMPs) released from damaged tissue [47]. Their role remains controversial. Microglia may also have a neuronal protective role against toxicity associated with stimulation of the NMDA glutamate receptors, as demonstrated by studies introducing microglia to previously microglia-free, organotypic slice cultures [48].

Microglia phagocytic activity removes cell debris, which is crucial to set the stage for axonal regeneration and structural remodelling of neural networks; myelin remnants may contribute to disruption of remyelination due to the release of growth inhibitors [49]. Furthermore, 
their clearance is influenced by the presence of proinflammatory cytokines such as TNFa, which have been shown to reduce the phagocytic activity of macrophages [50].

In parallel to the $\mathrm{T}$ helper 1 (Th1)/Th2 polarization concept relevant to $\mathrm{T}$ cells, macrophages may also be differentiated into an M1/M2 phenotype [51], an oversimplified concept that extends to the microglia as well. M1 macrophages, which are pro-inflammatory, contribute to generating free radicals and matrix metalloproteinase (MMP)9-mediated injury [47]. M2 macrophages promote the resolution of the inflammatory phase and its subsequent transition to healing and repair. In the presence of ischaemia, microglia and MDMs seem to favour differentiation into the M1 phenotype [52], which is associated with worse oxygen-glucose deprivation (OGD)induced neuronal loss [53]. Peripheral monocytes respond relatively later than microglia, i.e., on days 3-7 after ischaemic stroke [54]; those expressing genes favouring conversion to the M1 phenotype arrive earlier than those expressing genes favouring M2 polarization. Though their pro-inflammatory repertoire seems an obvious threat to mounting injury, their presence has been shown to be vital to the damage control of the ischaemic injury [55]. This may be explained by their ability to influence surrounding microglia/MDMs to convert into M2 phenotype macrophages [56] in addition to their own subsequent conversion to M2 phenotype macrophages. The players controlling the switch from the inflammatory phase to the repair phase, though yet to be defined, are probably a combination of factors. Firstly, M1 macrophages release TGF $\beta$ and VEGF once in the area of injury [57]. Secondly, dying cells release CX3CL1, which attracts M2 macrophages, mainly since they have a higher level of expression of corresponding receptors [58-60]. Both of these are associated with wound healing and tissue remodelling.

\section{The Role of VEGF}

Not only are the pericytes and astrocytes better able to adapt to the HI insult, they have also been shown to be vital in reducing injury through the secretion of protective factors, such as VEGF. VEGF exists as a family of 6 homologous members: VEGF-A, $-\mathrm{B},-\mathrm{C},-\mathrm{D}$, and $-\mathrm{E}$, as well as placental growth factor [61]. They bind to tyrosine kinase receptors known as VEGF receptors, and are prominently involved in coordinating the development and regulation of blood vessels. The protective role of
VEGF lies in increasing the survival of endothelial cells and reducing the volume of infarcted tissue via the inhibition of apoptotic mechanisms $[62,63]$.

However, VEGF contributes at the same time to increased BBB permeability via the destabilization of junctional proteins, including the tight junctions and adherens junctions [64]. This leads to vasogenic oedema, and may provide the link between increased BBB permeability and the pathophysiological inflammation in HIE [65]. Due to the diversity of the VEGF family, it is possible that the conflicting roles of VEGF following HI brain injury can be explained by the interactions between the different forms of VEGF and their corresponding receptors.

One of the important contributors to VEGF upregulation is $\mathrm{HIF}_{1 a}$ [66]. Hypoxia initiates the activation of this factor, resulting in the expression of genes responsible for angiogenesis. Similar to VEGF, Baburamani et al. [39] report conflicting effects of $\mathrm{HIF}_{1 \alpha}$ subsequent to $\mathrm{HI}$ insult and suggest that time post-injury is a determining factor. Acutely, the absence of $\mathrm{HIF}_{1 \alpha}$ has been associated with a reduced degree of injury [67]. Over a longer time course, however, mice unable to express $\mathrm{HIF}_{1 \alpha}$ were found to have a worse outcome than wild-type controls [68].

\section{A Reversal of Roles: Impact of BBB Dysfunction on the Pathophysiology of HIE}

Ek et al. [40] have shown a correlation between areas of disrupted BBB function and areas of infarction in the brain. Nedelcu et al. [69] noted that a moderate HI insult in the brain of postnatal day 7 (P7) rats produced a first phase of cytotoxic oedema, which was followed $4 \mathrm{~h}$ later by a second wave of cytotoxic oedema and new development of vasogenic oedema. Cerebral vasogenic oedema develops in the presence of increased BBB permeability, allowing for an unregulated accumulation of water content in brain tissue [70].

The expression of aquaporin 4 (AQP4), the major water channel of the mammalian brain [71], appears to be concentrated at the end-feet of the astrocytic component of the NVU [72]. AQP4 does not act solely as a regulator of water flow, it also serves other physiological functions [73]. AQP4 may control the flow of water bidirectionally, due to the observation that its absence can have 2 opposing outcomes in different types of pathology $[74,75]$. The absence of AQP4 reduces the severity of the oedema during the acute phase of HI injury. However, when oxygenation is reintroduced, the absence of AQP4 results in a longer time taken to clear the excess water [76].
6
Dev Neurosci

DOI: $10.1159 / 000467392$ 
The increase in BBB permeability may contribute to $\mathrm{HI}$ injury of the brain through the increased exposure of brain tissue to inflammatory mediators. One of the downstream pathways linked to TNFa, which is released in HIE, involves the activation of MMPs [77]. These proteolytic enzymes, especially MMP3 and MMP9, have been implicated in BBB disruption due to proteolysis of ECM proteins and cleavage of tight junctions, resulting in oedema and haemorrhage $[78,79]$. Therapeutic hypother$\mathrm{mia}(\mathrm{TH})$ is the only effective treatment in clinical use at present that intervenes at the level of the pathological mechanisms of HIE. In the clinical setting, TH has been shown to be effective when commenced within $6 \mathrm{~h}$ after birth $[80,81]$. From the point of view of the BBB, TH has been shown to reduce the activity of enzymes, especially that of MMPs, as well as maintain ECM molecular and cellular integrity $[82,83]$.

\section{Exploitation of Molecular Exchanges across the BBB to Increase Drug Delivery to Injured Brain Parenchyma}

An early increase in BBB permeability has been noted after $\mathrm{HI}$ insult, and we also know that neuroprotective interventions are more likely to be effective if commenced early. Therefore, we may postulate there to be a time window, as yet not clearly defined, in which effective drug delivery through the BBB may optimally exert a protective effect. The second concept is the targeting of changes in the BBB and how we can modulate these in an attempt to repair the injury caused in HIE.

The BBB has, at times, been mistakenly regarded as one and the same as the blood-CSF barrier [84]. While the $\mathrm{BBB}$ is spread across the capillaries of the brain, the blood-CSF barrier is focused at the choroid plexus in the ventricles. In the attempts to overcome the restrictions of the BBB, the solution of utilizing the blood-CSF barrier for the delivery of drugs into the intrathecal compartment was developed. However, this mode of delivery is limited by differentials in diffusion rates; diffusion from the CSF into the bloodstream is faster than direct diffusion from the CSF into brain tissue, so, paradoxically, drugs introduced into the CSF compartment are more likely to reach the brain parenchyma via the bloodstream and across the $\mathrm{BBB}$, rather than directly by passage into the brain tissue.

\section{MTH Technology: The Potential Role of Carrier-Mediated and Receptor-Mediated Transporters}

The BBB has been considered as the single most important limiting factor in the development of neurotherapeutic drugs [13]. This is partly because reliance on high-throughput screening (HTS) is more likely to select molecules of high molecular weights. Hydrophobic molecules with a molecular weight of $<400$ Da cross the BBB by free diffusion, while hydrophilic and large molecules gain access either via the carrier-mediated or receptormediated transport (RMT) system [84].

These systems transport molecules which retain the generic structures of the original substrates which the carriers and receptor transporters recognize as their target. This concept has led to the utilization of the intrinsic mechanism of the BBB to enable drug delivery in the form of molecular Trojan horse (MTH) technology. This relies on combining biologic therapeutics with monoclonal antibodies (MAbs, which are specific for receptors across the BBB), which take up substances from the periphery via RMT systems, such as insulin and transferrin $[14,85]$. Two of these genetically engineered MAbs are fusion proteins with IgG portions targeted against the human insulin receptor (HIR) and transferrin receptor (Tfr), i.e., HIRMAb and TfrMAb [85].

At present, all the evidence for the effectiveness of this technology is extrapolated from adult models. The final consensus on the functional maturity of the BBB in the fetus and the newborn has not been reached. On an optimistic note, inward transport, including the RMT for transferrin, across the BBB has been shown to function in the fetal and newborn brain [23].

The utility of MTH has enabled large molecules such as TNFa inhibitors [86] and erythropoietin [87] to be delivered across the BBB. We use these examples as agents being investigated for the treatment of HIE [88]. They have been shown to fulfil several criteria for effective MTH technology, including having a higher affinity of the fusion protein than the MAb enly for its target [89] as well as having a higher uptake across the $\mathrm{BBB}$ via a higher affinity for the specific RMT system [86].

Most studies of MTH technology have focused on the effect of these fusion proteins in adult models of acute stroke when assessing the impact on pathology, and they have demonstrated a reduction in infarct volume [90, 91]. Given that a number of the pathophysiology mechanisms are the same as those seen in stroke provides hope that this technology may be applicable not just to HIE but also 
neonatal encephalopathy from other causes. These studies await translation from the laboratory models to the clinic.

\section{Stem Cell Therapy}

Another exciting innovation that builds upon the concepts of the synergy of action between the different cells of the NVU is cell-based therapy. While deriving new cells from stem cells and progenitor cells is surrounded by much controversy, it remains, in theory, an attractive proposal for the repair and prevention of further injury to the brain. Cell-based therapies can be derived from various sources including umbilical cord blood, bone marrow, embryonic nervous tissue, and even adult brains [92]. Of interest in the BBB and indeed the nervous system, stem cells from umbilical cord blood are considered to be advantageous because they are a rich source of endothelial progenitor cells (EPCs) [93], cells which have just begun to change our understanding of vascular development, injury, and repair.

EPCs are a population of stem cells which are activated and recruited from sources including the bone marrow, umbilical cord blood, and peripheral blood, in reaction to hypoxia $[94,95]$. Their discovery led to the new concept of vasculogenesis [96]; this is the development of new blood vessels by the recruitment and maturation of EPCs, in contrast to angiogenesis whereby new blood vessels are formed from proliferation of the pre-existing endothelium. Thus, it was hypothesized that harnessing the potential of EPCs in promoting neovascularization in the presence of ischaemic injury [97] would be valuable as a novel therapeutic intervention [98]. Indeed, several studies which have begun to assess the impact of the activation of
EPCs in the presence of ischaemic injury have demonstrated that EPC treatment reduces infarct volume, improves deficits in cognitive learning and motor skills, and is associated with the recovery of regional cortical blood flow $[99,100]$.

However, as a note of caution: EPC treatment has been linked with the production of nitric oxide and VEGF [101]. While the properties of EPCs as growth factors and vasodilators may contribute to the restoration of blood flow to the ischaemic regions, a consensus on the effect of restoring cerebral blood flow and its impact on HIE has yet to be reached. Furthermore, these molecules have also been associated with BBB breakdown as well as the excitotoxic damage noted in HIE. The huge potential of EPC therapy has to be balanced with a need for the in-depth study of its potential risks and the harmful contributions it may make to the pathways of HI injury.

\section{Conclusion}

In this review, we started with our understanding of the structure and function of the BBB. We went on to discuss the effects of $\mathrm{HI}$ injury of the immature brain on the $\mathrm{BBB}$, and finally we touched on exciting therapeutic options linked to the targeting of the BBB, including MTH technology and stem cell therapy. These developments offer new hope for the improved management of HIE in the future.

\section{Disclosure Statement}

None of the authors has any conflict of interest to declare.

\section{References}

1 Volpe JJ: Hypoxic-ischemic encephalopathy: clinical aspects; in Volpe JJ (ed): Neurology of the Newborn, ed 5. Philadelphia, Saunders, 2008, pp 400-480.

2 Bennet L, Tan S, Van den Heuij L, Derrick M, Groenendaal F, van Bel F, et al: Cell therapy for neonatal hypoxia-ischemia and cerebral palsy. Ann Neurol 2012;71:589-600.

3 Colbourne F, Corbett D: Delayed postischemic hypothermia: a six-month survival study using behavioral and histological assessments of neuroprotection. J Neurosci 1995;15:7250-7260.
4 Geddes R, Vannucci RC, Vannucci SJ: Delayed cerebral atrophy following moderate hypoxia-ischemia in the immature rat. Dev Neurosci 2016;23:180-185.

5 Northington FJ, Graham EM, Martin LJ: Apoptosis in perinatal hypoxic-ischemic brain injury: how important is it and should it be inhibited? Brain Res Brain Res Rev 2005; 50:244-257.

6 Abbott NJ, Rönnbäck L, Hansson E: Astro cyte-endothelial interactions at the bloodbrain barrier. Nat Rev Neurosci 2006;7:4153.
7 Wolburg H, Lippoldt A: Tight junctions of the blood-brain barrier: development, composition and regulation. Vascul Pharmacol 2002; 38:323-337.

8 Hawkins BT, Davis TP: The blood-brain barrier/neurovascular unit in health and disease. Pharmacol Rev 2005;57:173-185.

9 Pardridge WM: Blood-brain barrier drug targeting: the future of brain drug development. Mol Interv 2003;3:90-105, 151

10 Neuwelt EA: Mechanisms of disease: the blood-brain barrier. Neurosurgery 2004;54: 131-140; discussion 141-142. 
11 Zlokovic BV: Neurovascular pathways to neurodegeneration in Alzheimer's disease and other disorders. Nat Rev Neurosci 2011; 12:723-738.

12 Torbett BE, Baird A, Eliceiri BP: Understanding the rules of the road: proteomic approaches to interrogate the blood brain barrier. Front Neurosci 2015;9:70

13 Pardridge WM: The blood-brain barrier: bottleneck in brain drug development. NeuroRx 2005;2:3-14.

14 Pardridge WM: Molecular Trojan horses for blood-brain barrier drug delivery. Discov Med 2016;6:139-143.

15 Butt AM, Jones HC, Abbott NJ: Electrical resistance across the blood-brain barrier in anaesthetized rats: a developmental study. J Physiol 1990;429:47-62.

16 Zhao Z, Nelson AR, Betsholtz C, Zlokovic BV: Establishment and dysfunction of the bloodbrain barrier. Cell 2015;163:1064-1078.

17 Nitta T, Hata M, Gotoh S, Seo Y, Sasaki H, Hashimoto N, et al: Size-selective loosening of the blood-brain barrier in claudin-5-deficient mice. J Cell Biol 2003;161:653-660.

18 Tietz S, Engelhardt B: Brain barriers: Crosstalk between complex tight junctions and adherens junctions. J Cell Biol 2015;209:493-506.

19 Armulik A, Genove G, Betsholtz C: Pericytes: developmental, physiological, and pathological perspectives, problems, and promises. Dev Cell 2011;21:193-215

20 Lindahl P, Johansson BR, Levéen P, Betsholtz C: Pericyte loss and microaneurysm formation in PDGF-B-deficient mice. Science 1997; 277:242-245.

21 Tallquist MD, French WJ, Soriano P: Additive effects of PDGF receptor beta signaling pathways in vascular smooth muscle cell development. PLoS Biol 2003;1:E52.

22 Daneman R, Zhou L, Kebede AA, Barres BA: Pericytes are required for blood-brain barrier integrity during embryogenesis. Nature 2010; 468:562-566.

23 Saunders NR, Liddelow SA, Dziegielewska KM: Barrier mechanisms in the developing brain. Front Pharmacol 2012;3:46.

24 Janzer RC, Raff MC: Astrocytes induce bloodbrain barrier properties in endothelial cells. Nature 1987;325:253-257.

25 Holash JA, Noden DM, Stewart PA: Re-evaluating the role of astrocytes in blood-brain barrier induction. Dev Dyn 1993;197:14-25.

26 Ramsauer M, Krause D, Dermietzel R: Angiogenesis of the blood-brain barrier in vitro and the function of cerebral pericytes. FASEB J 2002;16:1274-1276.

27 Ginhoux F, Lim S, Hoeffel G, Low D, Huber T: Origin and differentiation of microglia. Front Cell Neurosci 2013;7:45

28 Ransohoff RM, Cardona AE: The myeloid cells of the central nervous system parenchyma. Nature 2010;468:253-262.

$29 \mathrm{He} \mathrm{H}$, Mack JJ, Guc E, Warren CM, Squadrito ML, Kilarski WW, et al: Perivascular macrophages limit permeability. Arterioscler Thromb Vasc Biol 2016;36:2203-2212.
30 Wang Y, Rattner A, Zhou Y, Williams J, Smallwood PM, Nathans J: Norrin/Frizzled4 signaling in retinal vascular development and blood brain barrier plasticity. Cell 2012;151: 1332-1344.

31 Liebner S, Corada M, Bangsow T, Babbage J, Taddei A, Czupalla CJ, et al: Wnt/ $\beta$-catenin signaling controls development of the bloodbrain barrier. J Cell Biol 2008;183:409-417.

32 Alvarez JI, Dodelet-Devillers A, Kebir H, Ifergan I, Fabre PJ, Terouz S, et al: The Hedgehog pathway promotes blood-brain barrier integrity and CNS immune quiescence. Science 2011;334:1727-1731.

33 Tenreiro M, Ferreira R, Bernardino L, Brito MA: Cellular response of the blood-brain barrier to injury: potential biomarkers and therapeutic targets for brain regeneration. Neurobiol Dis 2016;91:262-273.

34 Chivet M, Hemming F, Pernet-Gallay K, Fraboulet S, Sadoul R: Emerging role of neuronal exosomes in the central nervous system. Front Physiol 2012;3:145.

35 Pant S, Hilton H, Burczynski ME: The multifaceted exosome: biogenesis, role in normal and aberrant cellular function, and frontiers for pharmacological and biomarker opportunities. Biochem Pharmacol 2012;83:1484-1494.

36 Haqqani AS, Delaney CE, Tremblay T-L, Sodja C, Sandhu JK, Stanimirovic DB: Method for isolation and molecular characterization of extracellular microvesicles released from brain endothelial cells. Fluids Barriers CNS 2013;10:4.

37 Grontoft O: Intracranial haemorrhage and blood-brain barrier problems in the newborn; a pathologico-anatomical and experimental investigation. Acta Pathol Microbiol Scand Suppl 1954;100:8-109.

38 Dziegielewska KM, Evans CA, Malinowska DH, Møllgård K, Reynolds JM, Reynolds ML et al: Studies of the development of brain barrier systems to lipid insoluble molecules in fetal sheep. J Physiol 1979;292:207-231.

39 Baburamani AA, Ek CJ, Walker DW, CastilloMelendez M: Vulnerability of the developing brain to hypoxic-ischemic damage: contribution of the cerebral vasculature to injury and repair? Front Physiol 2012;3:424.

40 Ek CJ, D’Angelo B, Baburamani AA, Lehner C, Leverin AL, Smith PL, et al: Brain barrier properties and cerebral blood flow in neonatal mice exposed to cerebral hypoxia-ischemia. J Cereb Blood Flow Metab 2015;35:818-827.

41 Muramatsu K, Fukuda A, Togari H, Wada Y, Nishino H: Vulnerability to cerebral hypoxicischemic insult in neonatal but not in adult rats is in parallel with disruption of the bloodbrain barrier. Stroke 1997;28:2281-2288; discussion 2288-2289.

42 Chen X, Threlkeld SW, Cummings EE, Juan I, Makeyev O, Besio WG, et al: Ischemiareperfusion impairs blood-brain barrier function and alters tight junction protein expression in the ovine fetus. Neuroscience 2012 226:89-100.
43 Chen EI, Hewel J, Felding-Habermann B, Yates JR 3rd: Large-scale protein profiling by combination of protein fractionation and multidimensional protein identification technology (MudPIT). Mol Cell Proteomics 2006; 5:53-56.

44 Baskaya MK, Rao AM, Dogan A, Donaldson D, Dempsey RJ: The biphasic opening of the blood-brain barrier in the cortex and hippocampus after traumatic brain injury in rats. Neurosci Lett 1997;226:33-36.

45 Kumar A, Mittal R, Khanna HD, Basu S: Free radical injury and blood-brain barrier permeability in hypoxic-ischemic encephalopathy. Pediatrics 2008;122:722-727.

46 Engelhardt S, Patkar S, Ogunshola OO: Cellspecific blood-brain barrier regulation in health and disease: a focus on hypoxia. $\mathrm{Br} \mathrm{J}$ Pharmacol 2016;171:1210-1230.

47 An C, Shi Y, Li P, Hu X, Gan Y, Stetler RA, et al: Molecular dialogs between the ischemic brain and the peripheral immune system: dualistic roles in injury and repair. Prog Neurobiol 2014;115:6-24.

48 Hellwig S, Heinrich A, Biber K: The brain's best friend: microglial neurotoxicity revisited. Front Cell Neurosci 2013;7:71.

49 Kotter MR, Li WW, Zhao C, Franklin RJ: Myelin impairs CNS remyelination by inhibiting oligodendrocyte precursor cell differentiation. J Neurosci 2006;26:328-332.

50 Neumann H, Kotter MR, Franklin RJ: Debris clearance by microglia: an essential link between degeneration and regeneration. Brain 2009;132(pt 2):288-295.

51 David S, Kroner A: Repertoire of microglial and macrophage responses after spinal cord injury. Nat Rev Neurosci 2011;12:388-399.

52 Ritzel RM, Patel AR, Grenier JM, Crapser J, Verma R, Jellison ER, et al: Functional differences between microglia and monocytes after ischemic stroke. J Neuroinflammation 2015; 12:106.

53 Hu X, Li P, Guo Y, Wang H, Leak RK, Chen $S$, et al: Microglia/macrophage polarization dynamics reveal novel mechanism of injury expansion after focal cerebral ischemia. Stroke 2012;43:3063-3070.

54 Breckwoldt MO, Chen JW, Stangenberg L, Aikawa E, Rodriguez E, Qiu S, et al: Tracking the inflammatory response in stroke in vivo by sensing the enzyme myeloperoxidase. Proc Natl Acad Sci USA 2008;105:18584-18589.

55 Gliem M, Mausberg AK, Lee JI, Simiantonakis I, van Rooijen N, Hartung HP, et al: Macrophages prevent hemorrhagic infarct transformation in murine stroke models. Ann Neurol 2012;71:743-752.

56 Chu HX, Broughton BR, Kim HA, Lee S, Drummond GR, Sobey CG: Evidence that Ly6 $\mathrm{C}^{\text {hi }}$ monocytes are protective in acute ischemic stroke by promoting M2 macrophage polarization. Stroke 2015;46:1929-1937.

57 Crane MJ, Daley JM, van Houtte O, Brancato SK, Henry WL Jr, Albina JE: The monocyte to macrophage transition in the murine sterile wound. PLoS One 2014;9:e86660.
HIE and the Blood-Brain Barrier in Neonates
Dev Neurosci

DOI: $10.1159 / 000467392$ 
58 Noda M, Doi Y, Liang J, Kawanokuchi J, Sonobe $\mathrm{Y}$, Takeuchi $\mathrm{H}$, et al: Fractalkine attenuates excito-neurotoxicity via microglial clearance of damaged neurons and antioxidant enzyme heme oxygenase-1 expression. J Biol Chem 2011;286:2308-2319.

59 Elliott MR, Chekeni FB, Trampont PC, Lazarowski ER, Kadl A, Walk SF, et al: Nucleotides released by apoptotic cells act as a find-me signal to promote phagocytic clearance. Nature 2009;461:282-286.

60 Brown GC, Neher JJ: Eaten alive! Cell death by primary phagocytosis: "phagoptosis." Trends Biochem Sci 2012;37:325-332.

61 Nakayama Masanori BP: Coordination of VEGF receptor trafficking and signaling by coreceptors. 2013;319:1340-1347.

62 Feng Y, Rhodes PG, Bhatt AJ: Neuroprotective effects of vascular endothelial growth factor following hypoxic ischemic brain injury in neonatal rats. Pediatr Res 2008;64:370-374.

63 Schmid-Brunclik N, Bürgi-Taboada C, Antoniou X, Gassmann M, Ogunshola OO: Astrocyte responses to injury: VEGF simultaneously modulates cell death and proliferation. Am J Physiol Regul Integr Comp Physiol 2008; 295:R864-R873.

64 Wang W, Dentler WL, Borchardt RT: VEGF increases BMEC monolayer permeability by affecting occludin expression and tight junc tion assembly. Am J Physiol Heart Circ Physiol 2001;280:H434-H440.

65 Kaur C, Sivakumar V, Zhang Y, Ling EA Hypoxia-induced astrocytic reaction and increased vascular permeability in the rat cerebellum. Glia 2006;54:826-839.

66 Fan X, Heijnen CJ, van der Kooij MA, Groenendaal F, van Bel F: The role and regulation of hypoxia-inducible factor-1 $\alpha$ expression in brain development and neonatal hypoxic-ischemic brain injury. Brain Res Rev 2009;62:99-108

67 Chen W, Jadhav V, Tang J, Zhang JH: HIF-1a inhibition ameliorates neonatal brain injury in a rat pup hypoxic-ischemic model. Neurobiol Dis 2008;31:433-441.

68 Sheldon RA, Osredkar D, Lee CL, Jiang X, Mu D, Ferriero DM: HIF-1 $\alpha$-deficient mice have increased brain injury after neonatal hypoxiaischemia. Dev Neurosci 2009;31:452-458.

69 Nedelcu J, Klein MA, Aguzzi A, Boesiger P, Martin E: Biphasic edema after hypoxic-ischemic brain injury in neonatal rats reflects early neuronal and late glial damage. Pediatr Res 1999;46:297-304.

70 Klatzo I: Pathophysiological aspects of brain edema. Acta Neuropathol 1987;72:236-239.

71 King LS, Kozono D, Agre P: From structure to disease: the evolving tale of aquaporin biology. Nat Rev Mol Cell Biol 2004;5:687-698.

72 Assentoft M, Larsen BR, MacAulay N: Regulation and function of AQP4 in the central nervous system. Neurochem Res 2015;40: 2615-2627.

73 Nagelhus EA, Ottersen OP: Physiological roles of aquaporin-4 in brain. Physiol Rev 2013;93:1543-1562.
74 Manley GT, Fujimura M, Ma T, Noshita N, Filiz F, Bollen AW, et al: Aquaporin-4 deletion in mice reduces brain edema after acute water intoxication and ischemic stroke. Nat Med 2000;6:159-163.

75 Manley GT, Binder DK, Papadopoulos MC Verkman AS: New insights into water transport and edema in the central nervous system from phenotype analysis of aquaporin-4 null mice. Neuroscience 2004;129:983-991.

76 Fu X, Li Q, Feng Z, Mu D: The roles of aquaporin-4 in brain edema following neonatal hypoxia ischemia and reoxygenation in a cultured rat astrocyte model. Glia 2007;55:935941

77 Rosenberg GA: Matrix metalloproteinases and their multiple roles in neurodegenerative diseases. Lancet Neurol 2009;8:205-216.

78 Heo JH, Lucero J, Abumiya T, Koziol JA Copeland BR, del Zoppo GJ: Matrix metalloproteinases increase very early during experimental focal cerebral ischemia. J Cereb Blood Flow Metab 1999;19:624-633.

79 Lo EH, Dalkara T, Moskowitz MA: Mechanisms, challenges and opportunities in stroke. Nat Rev Neurosci 2003;4:399-415.

80 Shankaran S, Laptook AR, Ehrenkranz RA, Tyson JE, McDonald SA, Donovan EF, et al: Whole-body hypothermia for neonates with hypoxic-ischemic encephalopathy. N Engl J Med 2005;353:1574-1584.

81 Azzopardi DV, Strohm B, Edwards AD, Dyet L, Halliday HL, Juszczak E, et al: Moderate hypothermia to treat perinatal asphyxial encephalopathy. N Engl J Med 2009;361:13491358

82 Baumann E, Preston E, Slinn J, Stanimirovic D: Post-ischemic hypothermia attenuates loss of the vascular basement membrane proteins, agrin and SPARC, and the blood-brain barrier disruption after global cerebral ischemia. Brain Res 2009;1269:185-197.

83 Jurkovich GJ, Pitt RM, Curreri PW, Granger DN: Hypothermia prevents increased capillary permeability following ischemia-reperfusion injury. J Surg Res 1988;44:514-521.

84 Pardridge WM: Drug transport across the blood-brain barrier. J Cereb Blood Flow Metab 2012;32:1959-1972.

85 Pardridge WM: Targeted delivery of protein and gene medicines through the blood-brain barrier. Clin Pharmacol Ther 2015;97:347361.

86 Boado RJ, Hui EK, Lu JZ, Zhou QH, Pardridge WM: Selective targeting of a TNFR decoy receptor pharmaceutical to the primate brain as a receptor-specific IgG fusion protein. J Biotechnol 2010;146:84-91.

87 Boado RJ, Hui EK, Lu JZ, Pardridge WM: Drug targeting of erythropoietin across the primate blood-brain barrier with an IgG molecular Trojan horse. J Pharmacol Exp Ther 2010;333:961-969.
88 Douglas-Escobar M, Weiss MD: Hypoxic ischemic encephalopathy: a review for the clinician. JAMA Pediatr 2015;169:397-403.

89 Zhou Q-H, Sumbria R, Hui EK-W, Lu JZ Boado RJ, Pardridge WM: Neuroprotection with a brain-penetrating biologic tumor necrosis factor inhibitor. J Pharmacol Exp Ther 2011;339:618-623

90 Sumbria RK, Boado RJ, Pardridge WM Brain protection from stroke with intravenous TNFa decoy receptor-Trojan horse fusion protein. J Cereb Blood Flow Metab 2012;32:1933-1938.

91 Sumbria RK, Boado RJ, Pardridge WM: Combination stroke therapy in the mouse with blood-brain barrier penetrating IgGGDNF and IgG-TNF decoy receptor fusion proteins. Brain Res 2013;1507:91-96.

92 Liao Y, Cotten M, Tan S, Kurtzberg J, Cairo MS: Rescuing the neonatal brain from hypoxic injury with autologous cord blood Bone Marrow Transplant 2013;48:890-900.

93 Pimentel-Coelho PM, Rosado-de-Castro $\mathrm{PH}$, da Fonseca LM, Mendez-Otero R: Umbilical cord blood mononuclear cell transplantation for neonatal hypoxic-ischemic encephalopathy. Pediatr Res 2012;71:464473.

94 Asahara T, Murohara T, Sullivan A, Silver $M$, van der Zee R, Li T, et al: Isolation of putative progenitor endothelial cells for angiogenesis. Science 1997;275:964-967.

95 Peichev M, Naiyer AJ, Pereira D, Zhu Z, Lane WJ, Williams M, et al: Expression of VEGFR-2 and AC133 by circulating human $\mathrm{CD} 34^{+}$cells identifies a population of functional endothelial precursors. Blood 2000; 95:952-958.

96 Zampetaki A, Kirton JP, Xu Q: Vascular repair by endothelial progenitor cells. Cardiovasc Res 2008;78:413-421.

97 Zhang ZG, Zhang L, Jiang Q, Chopp M: Bone marrow-derived endothelial progenitor cells participate in cerebral neovascularization after focal cerebral ischemia in the adult mouse. Circ Res 2002;90:284-288.

98 Castillo-Melendez M, Yawno T, Jenkin G, Miller SL: Stem cell therapy to protect and repair the developing brain: a review of mechanisms of action of cord blood and amnion epithelial derived cells. Front Neurosci 2013;7:194

99 Fan Y, Shen F, Frenzel T, Zhu W, Ye J, Liu J, et al: Endothelial progenitor cell transplantation improves long-term outcome in mice. Ann Neurol 2010;67:488-497.

100 Ohta T, Kikuta K, Imamura H, Takagi Y, Nishimura M, Arakawa Y, et al: Administration of ex vivo-expanded bone marrow-derived endothelial progenitor cells attenuates focal cerebral ischemia-reperfusion injury in rats. Neurosurgery 2006;59:679-686.

101 Hristov M, Weber C: Endothelial progenitor cells: characterization, pathophysiology, and possible clinical relevance. J Cell Mol Med 2004;8:498-508. 